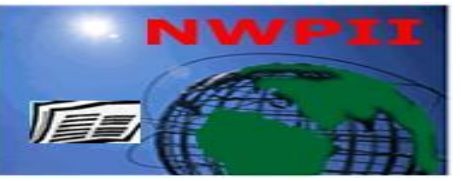

American Journal of Biomedical Sciences

ISSN: 1937-9080

nwpii.com/ajbms

\title{
Vitamin E Supplementation Modulates Endotoxin-induced Liver Damage in a Rat Model
}

\author{
Sushma Bharrhan ${ }^{1}$, Kanwaljit Chopra ${ }^{2}$ and Praveen Rishi ${ }^{1^{*}}$ \\ ${ }^{1}$ Department of Microbiology, Panjab University, Chandigarh-160014, India. \\ ${ }^{2}$ University Institute of Pharmaceutical Sciences, Panjab University, Chandigarh-160014, India. \\ *Corresponding author \\ Dr. (Mrs.) Praveen Rishi \\ Department of Microbiology \\ Basic Medical Sciences Block \\ Panjab University, Chandigarh-160014. \\ INDIA \\ Telephone : (O) +91-172-2534146, 2541770; (M): +919888895206 \\ Fax : +91-172-541770(O) \\ Email: rishipraveen@yahoo.com
}

Received: 17 August 2009; | Revised: 29 September 2009; | Accepted:17 October 2009

\begin{abstract}
Vitamin E ( $\alpha$-Tocopherol $[\alpha-$ Toc] $)$ is the primary membrane bound, lipid-soluble, chain-breaking antioxidant that has been reported to protect against lipid peroxidation-induced tissue damage. Therefore, the present study was designed to investigate the protection afforded by $\alpha$-Tocopherol (vitamin E), if any, on LPS-induced liver injury in Wistar rats and to study the underlying mechanism of protection. Bacterial endotoxin $(10 \mathrm{mg} / \mathrm{Kg}$ body weight-prestandardized dose) was injected intraperitoneally and animals were sacrificed $8 \mathrm{~h}$ post-challenge. Vitamin E (35 mg/Kg body weight) was administered orally for 15 days prior to endotoxin challenge. Challenge with LPS resulted in a significant increase in the activities of serum transaminases and alkaline phosphatase along with histological alterations in the liver. These responses were associated with elevated levels of malondialdehyde (MDA) and reduced levels of glutathione, superoxide dismutase and catalase along with increased levels of tumor necrosis factor alpha (TNF- $\alpha$ ) in the liver homogenates. However, vitamin E supplementation attenuated the oxidative stress by reducing the levels of MDA, restoring the levels of glutathione, superoxide dismutase and catalase and decreasing the levels of TNF- $\alpha$. Decreased TNF- $\alpha$ levels after vitamin E supplementation might have resulted into the modulation of above mentioned biochemical changes resulting into amelioration of hepatic architecture. Vitamin E, therefore, seems to have a promising role for clinical manifestations due to oxidative stress.
\end{abstract}

Keywords: Endotoxin; Liver; Oxidative stress; $\alpha$-Tocopherol; Tumor necrosis factor alpha. 


\section{Introduction}

Lipopolysaccharide (LPS) or endotoxin, among the principal components of all Gramnegative bacteria, has been extensively studied as a major factor contributing to the pathogenesis of Gram-negative bacterial infections [1]. Endotoxin is a highly conserved cell wall component that is recognized by the immune system of higher vertebrates as a pathogen-associated molecular pattern (PAMP) and can elicit a systemic inflammatory response $[2,3]$.

LPS binding to immune cells initiates a cascade of events that up-regulate expression of the inflammatory cytokines including TNF- $\alpha[2$, $4,5]$. TNF- $\alpha$ stimulates the production of reactive oxygen species (ROS) and reactive nitrogen intermediates (RNIs) by activated macrophages causing liver damage due to the oxidative stress [6-9]. Additionally, LPS induces migration of activated polymorphonuclear leukocytes (PMNs) into the liver which constitutes another source of free radicals [10]. The oxidative stress thus generated, induces a rapid alteration in the antioxidant systems by depleting the cellular stores of endogenous antioxidants such as superoxide dismutase, catalase, glutathione and vitamin $\mathrm{E}[1,11,12]$. One approach to combat the bacterial product-induced oxidative stress is the use of antioxidant treatments through intraperitoneal, intravenous, or dietary administration $[2,13]$.

Vitamins are ideal antioxidants to increase tissue protection from oxidative stress due to their easy, effective and safe dietary administration in a large range of concentrations [3, 14]. Vitamin E $(\alpha$-Tocopherol $[(\alpha-$ Toc $])$ is the primary membrane bound, lipid-soluble, chain-breaking antioxidant that protects cell membranes against lipid peroxidation [15-18]. Vitamin E pre-treatment has been reported to be beneficial in preventing formaldehyde-induced tissue damage in rats $[16$, 19]. The preventive effect of vitamin $E$ on cypermethrin or endotoxin-induced oxidative stress in rat tissues is suggestive of its antioxidant activity [1, 20-24]. In addition to its antioxidative properties, treatment with vitamin $\mathrm{E}$ incorporated in liposomes has been shown to be beneficial in down-modulating airway inflammation induced by

Am. J. Biomed. Sci. 2010, 2(1), 51-62; doi: 10.5099/aj100100051 inhaled endotoxin and thereby providing significant protection against lung injury [25].

Since liver is implicated in almost all biological processes, its damage induces severe consequences of metabolism, immune response, detoxification and antimicrobial defense. However, not much information is available with respect to the effect of vitamin E on LPS-induced liver damage. The present study was therefore, carried out to evaluate the effect of vitamin E against oxidative liver injury in experimentallyinduced endotoxemic rats.

\section{Materials and methods}

\subsection{Agents}

Lipopolysaccharide (LPS from E. coli serotype 0111:B4) and $\alpha$ - Tocopherol were obtained from Sigma Aldrich Chemicals, St. Louis, MO, USA. The preparations were made fresh every time before the commencement of the experiment.

\subsection{Animals}

Female Wistar rats (150-200g) were procured from Central Animal House, Panjab University, Chandigarh (India). The animals were allowed free access to food (Ashirwad Industries Pvt Ltd, Punjab, India) and water ad-libitum. All experimental protocols were approved by the Institutional Animals Ethics Committee, Panjab University, Chandigarh (India).

\subsection{Experimental design}

Rats were divided into following groups each comprising of at-least 6-8 rats. For all the groups, dose of LPS was prepared in water for injection and that of $\alpha$-Tocopherol was prepared in olive oil. (1) Control group: Rats in this group were administered normal saline i.p., (2) Vehicle group (VEH): Rats in this group were administered olive oil orally (solvent for $\alpha$ - Tocopherol) for 15 days, (3) $\alpha$ - Tocopherol (TC) per se group: Animals in this group were supplemented with $\alpha$ - Tocopherol (35mg/kg body weight) orally for 15 days, (4) LPS challenged group: Rats in this group received a dose of LPS $(10 \mathrm{mg} / \mathrm{kg}$ body weight, pre-standardized dose) i.p., (5) $\boldsymbol{\alpha}$ - Tocopherol supplemented + LPS challenged group $(\mathrm{TC}+$

(c) 2010 by NWPII. All rights reserved. 
LPS): Animals in this group were supplemented with $\alpha$ - Tocopherol (35mg/kg body weight) orally for 15 days and then challenged with endotoxin on $16^{\text {th }}$ day

Animals in all these groups were sacrificed 8 hrs post-endotoxin challenge by cervical dislocation. Livers were removed quickly, rinsed in cold phosphate buffer saline (0.05 M, pH 7.4) and stored at $-20^{\circ} \mathrm{C}$ till further use.

\subsection{Markers of liver damage}

\subsubsection{Assessment of liver function}

Blood was collected by retro-orbital puncture from rats before they were sacrificed. Alanine aminotransferase (ALT) and aspartate aminotransferase (AST) enzyme activities in serum were determined by the method recommended by International Federation of Clinical Chemistry (IFCC) using ERBA test kits (ERBA Diagnostics, Mannheim, Germany). Alkaline phosphatase (ALP) was estimated by the p-nitrophenyl phosphate method recommended by German Society for Clinical Chemistry using Enzopak Diagnostic kit (Reckon Diagnostics, India).

\subsubsection{Histological studies}

Liver tissues removed aseptically from all the groups were cut into small pieces and fixed in 10 $\%$ buffered formalin. Samples were processed, stained with haematoxylin-eosin and examined under the light microscope. Histological processing and interpretation was done by Dr. B. N Datta, Ex-Professor of Pathology, Post Graduate Institute of Medical Education and Research, Chandigarh.

\subsection{Mechanistic studies}

To carry out the biochemical estimations, liver homogenates were prepared. Briefly, livers removed aseptically from all the groups were rinsed in isotonic saline solution and weighed. A $25 \%(\mathrm{w} / \mathrm{v})$ tissue homogenate in each case was prepared in $0.05 \mathrm{M}$ phosphate buffer saline $(\mathrm{pH}$ 7.4) using a Potter Elvehjen homogenizer. An aliquot of the liver homogenate was used for the estimation of lipid peroxidation and reduced glutathione levels. For the estimation of

Am. J. Biomed. Sci. 2010, 2(1), 51-62; doi: 10.5099/aj100100051 superoxide dismutase and catalase activities, post mitochondrial preparation was made. For this, the remaining tissue homogenates were centrifuged at $12,000 \mathrm{rpm}$ for $20 \mathrm{~min}$ at $4^{\circ} \mathrm{C}$ in a refrigerated centrifuge. The supernatants thus obtained were called as the post mitochondrial supernatants (PMS).

\subsubsection{Extent of peroxidative liver damage}

The quantitative measurement of lipid peroxidation in liver was performed according to the method of Wills [26]. The amount of malondialdehyde (MDA) formed, which is a measure of lipid peroxidation, was assayed by the reaction with thiobarbituric acid (TBA). In brief, to $0.5 \mathrm{ml}$ of liver homogenate, $0.5 \mathrm{ml}$ of Tris- $\mathrm{HCl}$ buffer $(0.1 \mathrm{M}, \mathrm{pH} 7.4)$ was added and the mixture was incubated at $37^{\circ} \mathrm{C}$ for $2 \mathrm{~h}$. Following incubation, $1.0 \mathrm{ml}$ of $10 \%(\mathrm{w} / \mathrm{v})$ ice-cold trichloroacetic acid (TCA) was added and the mixture was centrifuged at $1,000 \mathrm{rpm}$ for 10 minutes. To $1.0 \mathrm{ml}$ of supernatant (obtained after centrifugation), $1.0 \mathrm{ml}$ of $0.67 \%(\mathrm{w} / \mathrm{v}) \mathrm{TBA}$ was added and the mixture was kept in boiling water bath for $10 \mathrm{~min}$. After cooling the tubes with tap water, $1.0 \mathrm{ml}$ of distilled water was added and absorbance was measured at $532 \mathrm{~nm}$. The results were expressed as nanomoles of MDA per milligram of protein, using the molar extinction coefficient of chromophore (1.56 X $\left.10^{5} \mathrm{M}^{-1} \mathrm{~cm}^{-1}\right)$ for which protein content of tissue homogenates was calculated according to the method of Lowry et al. [27].

\subsubsection{Liver glutathione (GSH) assay}

GSH levels in the livers were estimated according to the method of Jollow et al. [28]. 1.0 $\mathrm{ml}$ of liver homogenate was precipitated with 1.0 $\mathrm{ml}$ of $4 \%$ sulphosalicylic acid. The samples were kept at $4^{\circ} \mathrm{C}$ for at least $1 \mathrm{~h}$, and then subjected to centrifugation at $2000 \mathrm{rpm}$ for $15 \mathrm{~min}$ at $4^{\circ} \mathrm{C}$. The assay mixture contained $0.1 \mathrm{ml}$ of supernatant, 0.2 $\mathrm{ml}$ of $0.01 \mathrm{M}, 5$, 5'-dithiobis 2-nitrobenzoic acid (DTNB) and $2.7 \mathrm{ml}$ phosphate buffer $(0.1 \mathrm{M}, \mathrm{pH}$ 8.0 ) in a total volume of $3.0 \mathrm{ml}$. The mixture was kept at room temperature for $10 \mathrm{~min}$. The yellow color that developed was measured at $412 \mathrm{~nm}$. The results were expressed as micromoles of GSH per milligram of protein.

(C) 2010 by NWPII. All rights reserved. 


\subsubsection{Liver superoxide dismutase (SOD) and catalase activities}

SOD activity was assayed according to the method of Kono [29]. The reaction was initiated by the addition of $0.5 \mathrm{ml}$ of hydroxylamine hydrochloride to the reaction mixture containing $2.0 \mathrm{ml}$ nitroblue tetrazolium (NBT) and $0.1 \mathrm{ml}$ PMS of liver homogenate. Change in absorbance was measured spectrophotometrically at $560 \mathrm{~nm}$. SOD activity was expressed as units of SOD per milligram of protein where one unit of activity is defined as the amount of SOD required to inhibit the rate of reduction of NBT by $50 \%$.

The catalase activity was assayed by the method of Luck [30]. The assay mixture consisted of $3.0 \mathrm{ml} \mathrm{H} \mathrm{O}_{2}$-phosphate buffer (0.05 M, pH 7.0) and $0.05 \mathrm{ml}$ of PMS taken directly in a cuvette. Change in absorbance was recorded spectrophotometrically at $240 \mathrm{~nm}$. The results were expressed as millimoles of $\mathrm{H}_{2} \mathrm{O}_{2}$ decomposed per min per mg protein using the molar extinction coefficient of the chromophore $\left(0.0394 \mathrm{mM}^{-1} \mathrm{~cm}^{-}\right.$ $\left.{ }^{1}\right)$.

\subsubsection{Liver TNF- $\alpha$ assay}

Assay for tumor necrosis factor (TNF- $\alpha$ ) was performed by ELISA in the liver homogenate in all the groups by commercially available cytokine assay kit (R\&D Systems, USA) according to the manufacturers instructions. Briefly, standards for TNF- $\alpha$ were dispensed in the 96 well microtitre plates pre-coated with monoclonal antibody specific for rat TNF- $\alpha$. To each of the designated wells, $50 \mu \mathrm{l}$ of each test sample and $50 \mu \mathrm{l}$ of assay diluent was added, the plates were sealed with acetate plate sealer and incubated at room temperature for $2 \mathrm{~h}$. Plates were then washed five times with the wash buffer and $100 \mu \mathrm{l}$ of rat TNF$\alpha$ conjugate was dispensed into each well. Plates were again sealed and incubated at room temperature for $2 \mathrm{~h}$, after which they were washed five times with the wash buffer and $100 \mu \mathrm{l}$ of substrate solution was dispensed into each well. Plates were finally incubated at room temperature (in dark) for $30 \mathrm{~min}$. $100 \mu \mathrm{l}$ of the stop solution was added into each well to stop the reaction and absorbance was read at $450 \mathrm{~nm}$. The results were expressed as picogram $/ \mathrm{ml}$ of the TNF- $\alpha$ released.
The ELISA was sensitive to 5 picogram $/ \mathrm{ml}$ of the TNF- $\alpha$ released.

\subsection{Statistical analysis}

Results were expressed as Mean \pm S.D. The inter group variation was measured by one way analysis of variance (ANOVA) followed by Fisher's least significant difference test. The statistical analysis was done using Jandel Sigma Stat Statistical Software version 2.0. Statistical significance of the results were calculated atleast at $\mathrm{p}<0.05$.

\section{Results}

\subsection{Liver function tests}

LPS caused a marked rise in serum levels of

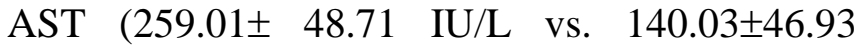
IU/L), ALT (129.77 \pm 48.56 IU/L vs. $63.06 \pm 8.04$ IU/L) and ALP $(870.87 \pm 139.52 \mathrm{IU} / \mathrm{L}$ vs. 251.63 $\pm 50.97 \mathrm{IU} / \mathrm{L})$. The activities of liver enzymes were decreased significantly $(p<0.05)$ on supplementation with tocopherol. Tocopherol per se had no effect on liver enzyme levels (Fig. 1a1c).

\subsection{Hepatic histoarchitechture}

Histological evaluation of liver tissues did not reveal any morphological alterations in the control group (Fig. 2a) and tocopherol per se (Fig. 2b). In contrast, livers of LPS-administered rats showed marked morphological disruption such as portal triaditis, Kupffer cell hyperplasia, necrosis and lymphocytic infiltration (Fig. 2c, 2d). Supplementation with tocopherol resulted in significant morphological protection (Fig. 2e, 2f).

\subsection{Malondialdehyde levels}

LPS caused a significant increase in lipid peroxidation as compared to control rats (125.71 \pm 41.85 nanomoles/mg protein vs. $51.45 \pm 8.48$ nanomoles/ $\mathrm{mg}$ protein in control). However, tocopherol significantly $(\mathrm{p}<0.01)$ attenuated LPS-induced increase in liver MDA levels (Fig. 3) when rats were supplemented with tocopherol for 15 days before LPS challenge. 


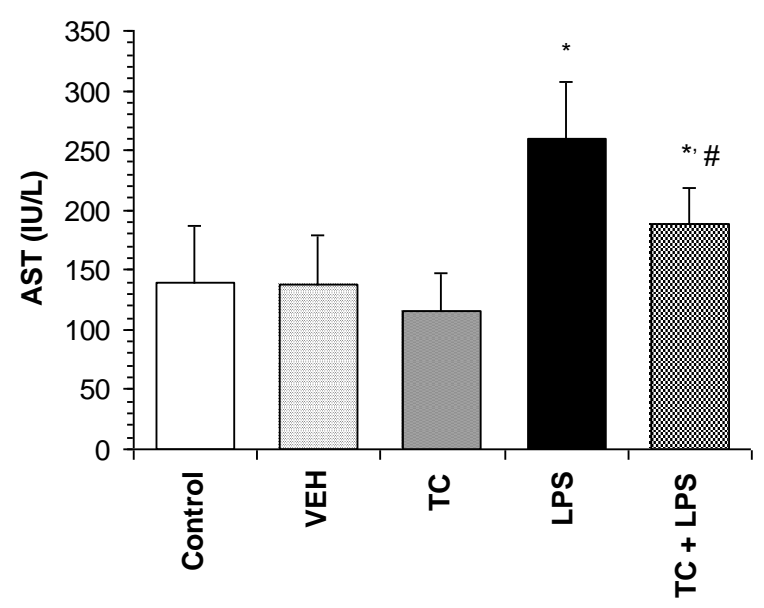

Fig. 1a

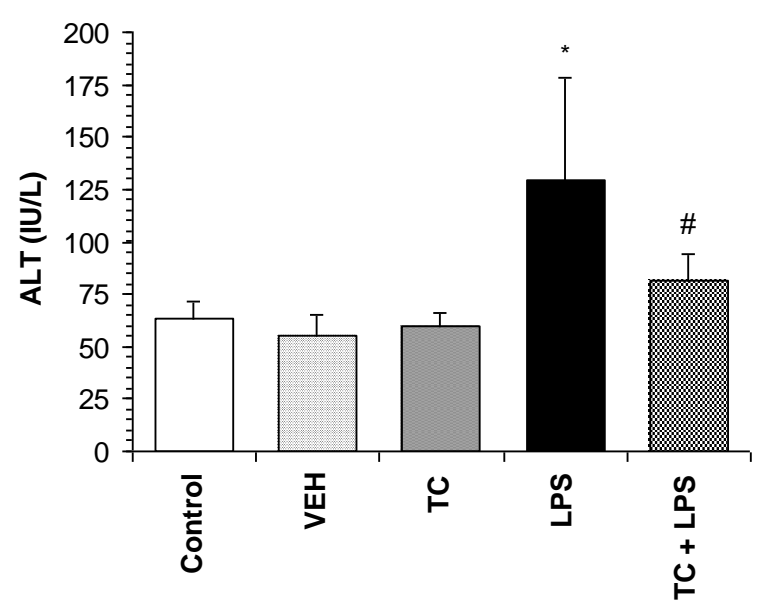

Fig. 1b

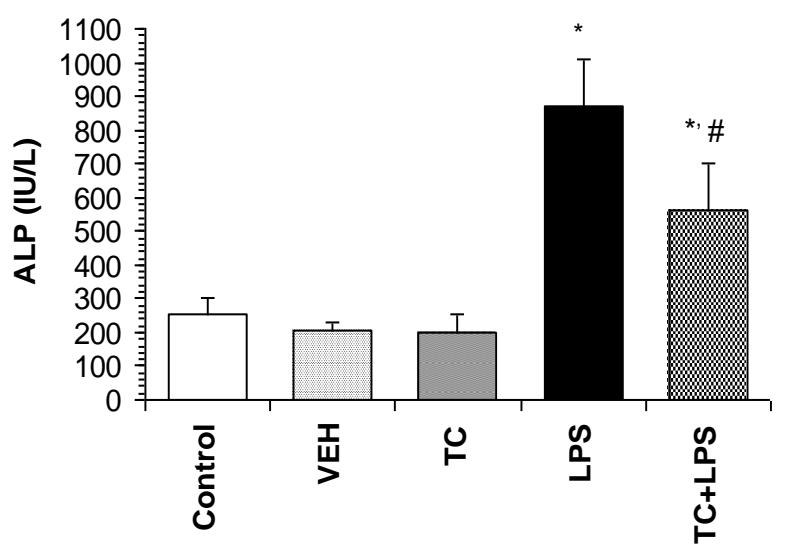

Fig. 1c

Fig 1a-1c: Effect of Tocopherol on (a) AST (b) ALT and (c) ALP levels in LPS-challenged rats compared to control or tocopherol administered rats. Values are expressed as mean \pm SD. $* p<0.05$ vs. control, Vehicle and Tocopherol per se; \#p<0.05 vs. LPS.

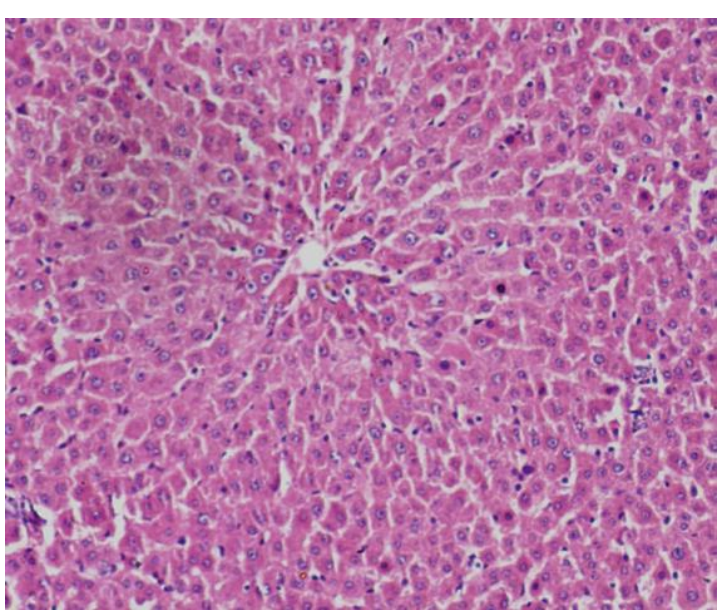

Fig. 2a

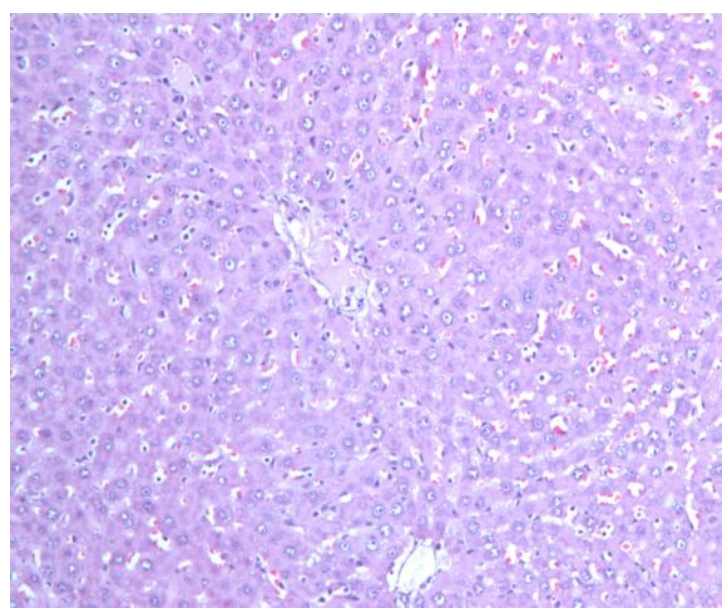

Fig. 2b

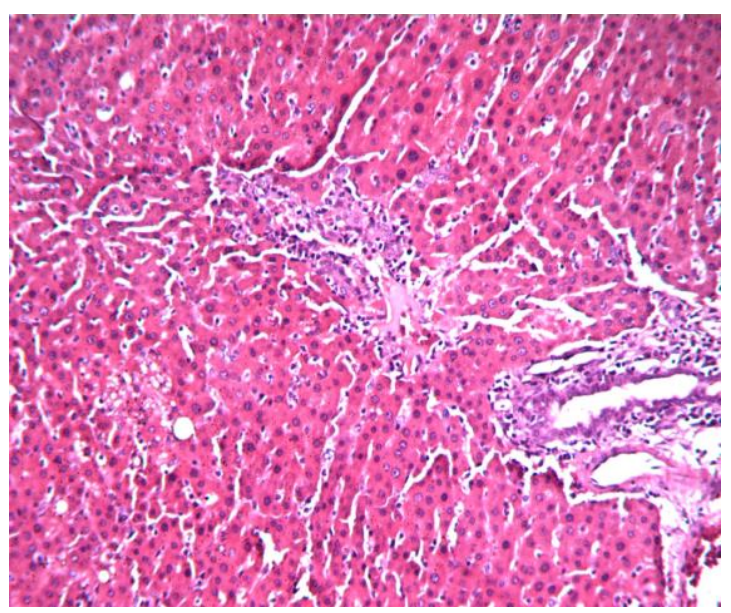

Fig. 2c 


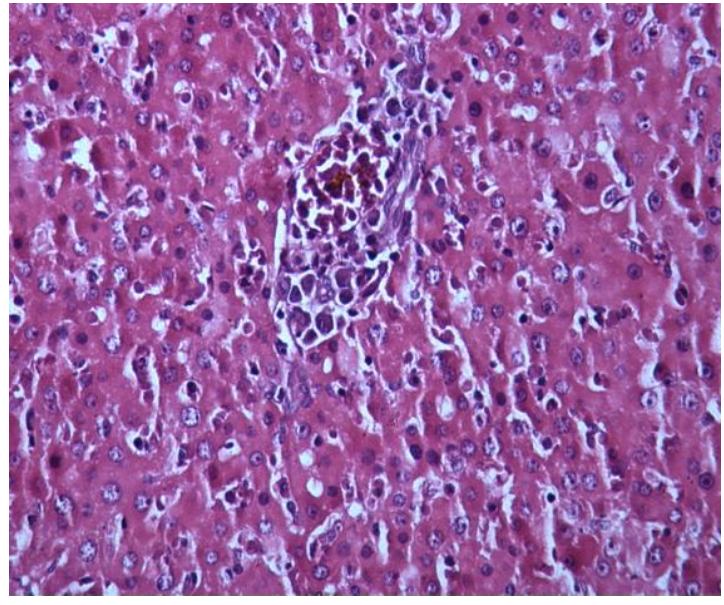

Fig. 2d

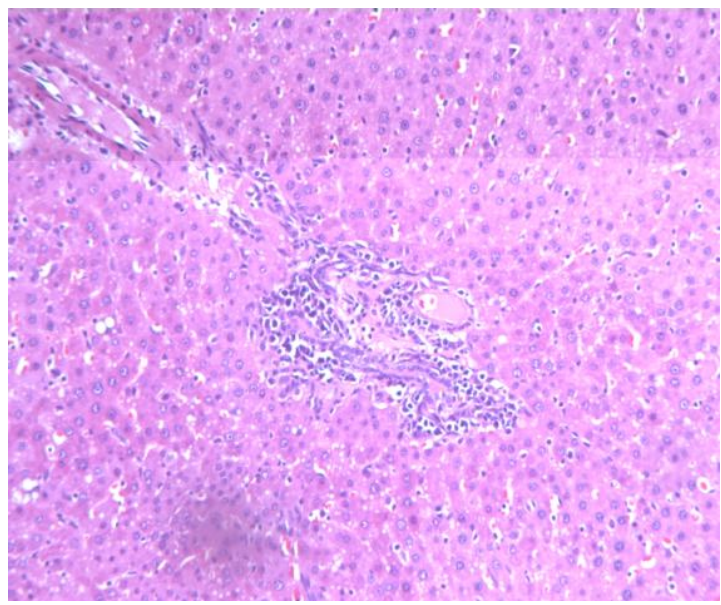

Fig 2e

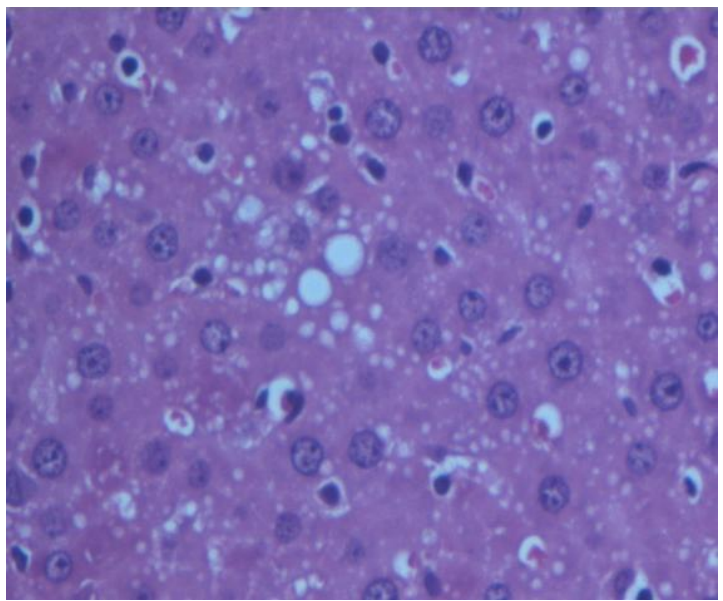

Fig $2 f$

Fig. 2a-2f: (2a) Photomicrograph of the normal / control liver of Wistar rat showing normal liver morphology (100 x); (2b) Photomicrograph of rat liver of tocopherol per se group showing normal liver morphology (100 x); (2c) Photomicrograph of liver 8 hours after LPS administration to rats showing two adjacent portal tracts showing considerable portal triaditis with some breach of lamina limitence indicating development of chronic hepatitis $(100 \mathrm{x})$; (2d) Photomicrograph of liver 8 hours after LPS administration to rats showing portal triaditis (portal tract distended with mononuclear cell infiltration). Surrounding liver showing significant Kupffer cell hyperplasia $(100 \mathrm{x})$; (2e) Photomicrograph of rat livers supplemented with tocopherol $(35 \mathrm{mg} / \mathrm{kg})$ for 15 days before LPS challenge showing moderate degree of lymphocytes and plasma cells in the portal tracts. The portal tracts are expanded but intact. Hepatocytes are normal $(100 \mathrm{x})$; (2f) Photomicrograph of rat livers supplemented with tocopherol $(35 \mathrm{mg} / \mathrm{kg})$ for 15 days before LPS challenge showing normal liver. Liver cells show mild diffuse microvesicular fatty change only (400 x).

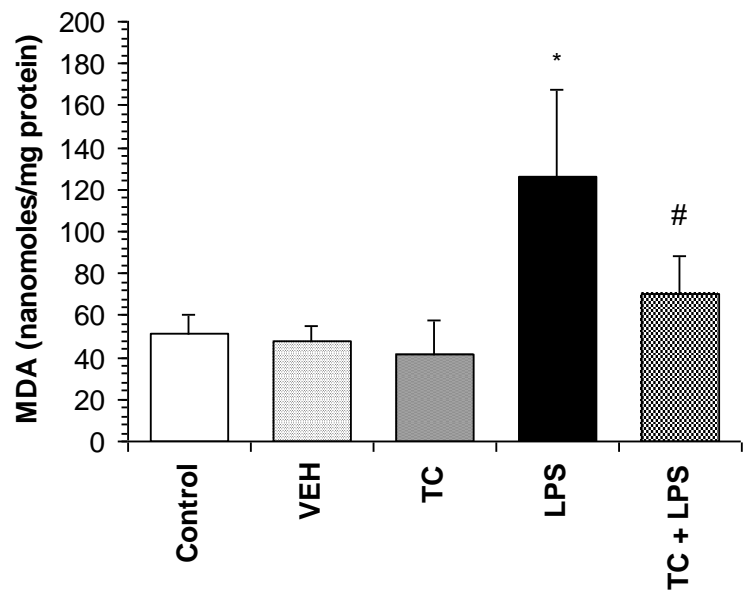

Fig 3: Effect of Tocopherol on liver MDA levels in LPS-challenged rats compared to control or tocopherol administered rats. Values are expressed as mean \pm SD. $* \mathrm{p}<0.05$ vs. control, Vehicle and Tocopherol per se; $\# \mathrm{p}<0.05$ vs. LPS.

\subsection{Glutathione levels}

LPS caused a significant decrease in GSH levels $(0.28 \pm 0.06 \mu$ moles $/ \mathrm{mg}$ protein vs. $0.52 \pm 0.12 \mu$ moles/ $\mathrm{mg}$ protein in control). Tocopherol supplementation significantly ameliorated LPS-induced depletion of GSH $(\mathrm{p}<0.05)$. However, tocopherol per se did not result in a significant alteration of GSH levels (Fig. 4).

\subsection{Levels of antioxidant enzymes}

LPS significantly reduced the levels of liver SOD and catalase as compared to the control 
group (1.9 and 1.5 fold, respectively). Tocopherol supplementation in LPS- challenged rats increased the SOD level in both pre and post-LPS challenged groups by 1.6 and 1.4 fold, respectively at $p<0.05$. However, the increase in SOD activity was significant even at $p<0.01$ in LPS challenged rats which were supplemented with tocopherol for 15 days (Fig. 5a). Catalase activity was also significantly increased at $\mathrm{p}<0.05$ only in tocopherol supplemented and LPS challenged group by 1.32 fold (Fig. 5b). Animals in the group treated with only tocopherol did not show any significant change in the antioxidant enzyme levels.

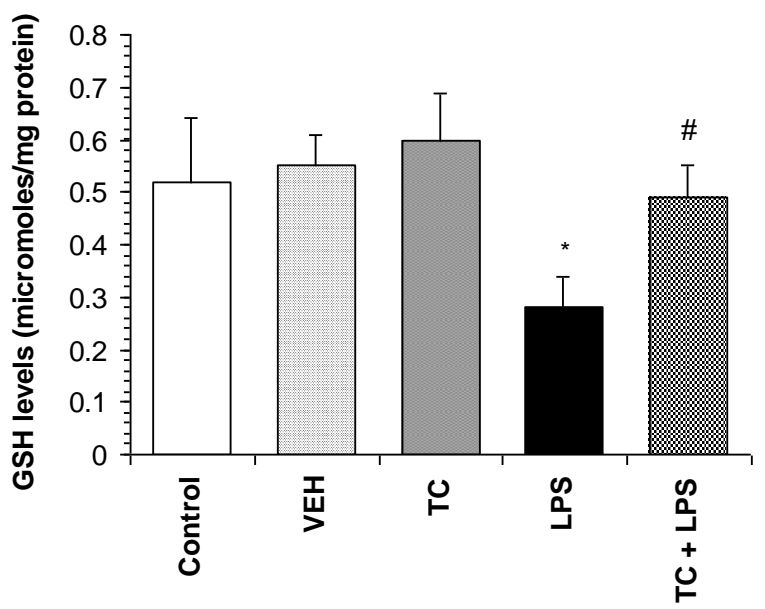

Fig 4: Effect of Tocopherol on liver GSH levels in LPS-challenged rats compared to control or tocopherol administered rats. Values are expressed as mean $\pm \mathrm{SD}$. $* p<0.05$ vs. control, Vehicle and Tocopherol per se; $\# \mathrm{p}<0.05$ vs. LPS.

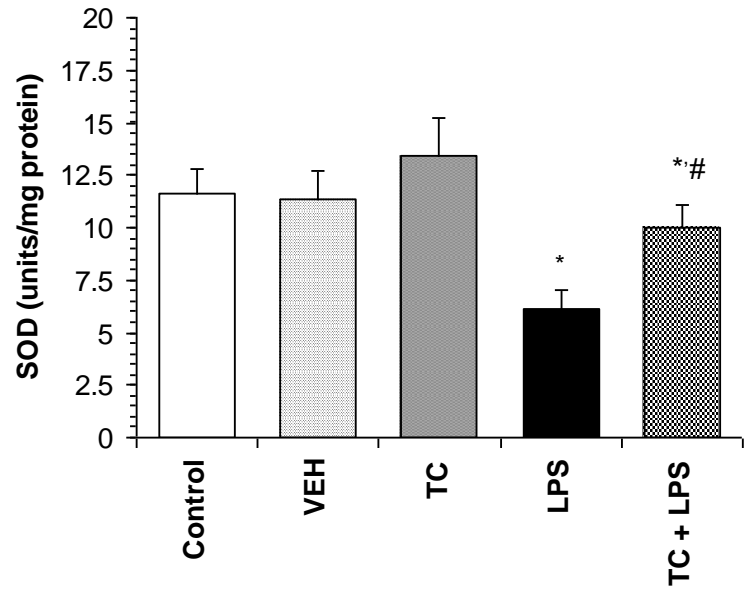

Fig. 5a

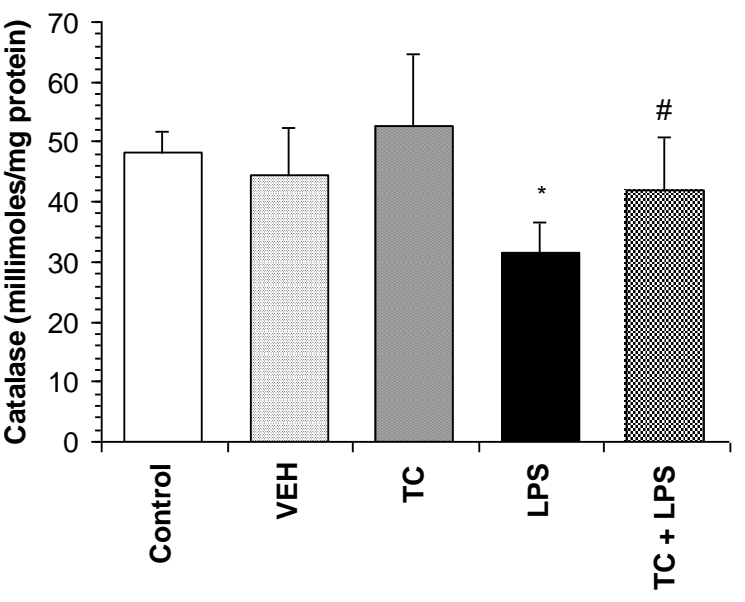

Fig. 5b

Fig 5a and 5b: Effect of Tocopherol on (5a) SOD activity and (5b) catalase activity in LPS-challenged rats compared to control or tocopherol administered rats. Values are expressed as mean \pm SD. ${ }^{*} \mathrm{p}<0.05$ vs. control, Vehicle and Tocopherol per se; \#p<0.05 vs. LPS.

\subsection{Liver TNF- $\alpha$ levels}

LPS challenge caused a marked rise in the levels of TNF- $\alpha$ compared to the control group $(609.0 \pm 104.0 \mathrm{pg} / \mathrm{ml}$ vs. $260.0 \pm 75.0 \mathrm{pg} / \mathrm{ml}$ in control). Administration of tocopherol preLPS challenge significantly decreased the levels of TNF- $\alpha$ by 1.48 fold at $\mathrm{p}<0.05$ (Fig. 6).

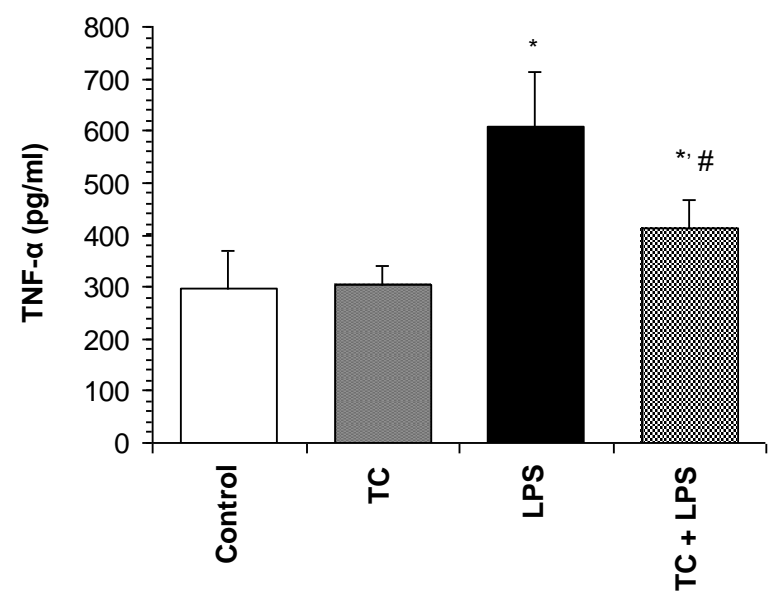

Fig 6: Effect of Tocopherol on TNF- $\alpha$ levels in LPSchallenged rats compared to control or tocopherol administered rats. Values are expressed as mean \pm SD. * $\mathrm{p}<0.05$ vs. control, Vehicle and Tocopherol per se; $\# p<0.05$ vs. LPS. 


\section{Discussion}

Antioxidants are being investigated for their ability to prevent cardiovascular, hepatic and pulmonary damage caused by LPS-induced production of ROS, peroxides and cytokines [14]. Vitamin $\mathrm{E}$ has been shown to protect the liver in several models of liver injury via inhibiting oxidative damage [16, 19, 21, 31-34]. The present study was therefore designed to study the detailed mechanism of protection offered by vitamin $\mathrm{E}$ against LPS-induced liver damage in rats in terms of biochemical, histological and immunological parameters.

The serum transaminases, AST and ALT and ALP show functional activity of liver. An increase in the activities of these enzymes indicates a generalized effect due to the toxin. Administration of tocopherol before LPS challenge resulted in a significant reduction in the serum levels of these enzymes. These results are in accordance with the earlier studies where pretreatment with vitamin $\mathrm{E}$ has been reported to confer protection against such changes in formaldehyde and monosodium glutamate induced-hepatotoxicity and oxidative stress in rats $[16,33]$. Protective effects of tocopherol in reducing the levels of hepatic markers correlated well with the histological findings in the present study. Supplementation with tocopherol decreased the incidence and severity of LPS-related histologic changes (like expanded but intact portal tracts, reduction in lymphocytic infiltration in the portal tracts). This observation is in accordance with results reported by Coskun et al. [35]. The anti-inflammatory effect of vitamin E may be indirectly related to inhibition of chemotaxis of neutrophils through inhibition of protein kinase $\mathrm{C}$, 5-lipoxygenase, tyrosine-kinase and cyclooxygenase, as has been suggested by Singh et al. [36].

Lipid peroxidation can cause changes in membrane fluidity and permeability and increase the rate of protein degradation, which eventually lead to cell lysis. Vitamin $\mathrm{E}$ has been used to prevent oxidative damage by interrupting the propagation of the oxidation of polyunsaturated fatty acids. In the present study also, vitamin E supplementation showed an antiperoxidative effect

Am. J. Biomed. Sci. 2010, 2(1), 51-62; doi: 10.5099/aj100100051 in the rat liver tissues by significantly decreasing the LPS-induced rise of liver MDA levels. This effect of vitamin E may be explained by its direct free radical scavenging property [37-39], which suggests that by preserving cellular integrity, it can protect against endotoxin-induced organ damage. Earlier also, the scavenging effect of vitamin $\mathrm{E}$ has been reported to attenuate endotoxin-induced oxidative stress in rat brain and sickness behavior in mice [2]. In the present study, inhibition of chemotaxis of leucocytes by vitamin E might have reduced the MDA levels, thus modulating the oxidative stress.

Host cells are protected from oxygen-derived radical injury by naturally occurring free-radical scavengers and antioxidant pathways, including vitamins $\mathrm{A}, \mathrm{C}$, and $\mathrm{E}$, glutathione, SOD, catalase, and glutathione peroxidase. However, the antioxidant defense mechanism fails either due to overproduction of free radicals or decreased activities of scavenging enzymes, or both, causing lipid peroxidation [40, 41]. Vitamin E activity has been mainly related to a peroxidase-contained complex antioxidant system defense, such as catalase and glutathione peroxidase [42]. Therefore, an increase in these antioxidant enzymes after vitamin E administration was expected.

In the present study, significant decrease in the activities of SOD and catalase along with reduced GSH levels was observed in the liver tissues from LPS challenged rats. This may result in hampered dismutation of superoxide anions and inefficient detoxification of $\mathrm{H}_{2} \mathrm{O}_{2}$ which results in formation of $\mathrm{OH}^{*}$ ions enhancing the peroxidation of membrane lipids thereby leading to oxidative damage in many tissues [43]. However, vitamin E supplementation was observed to increase the levels of GSH, SOD and catalase significantly in the LPS-challenged animals in the present investigation. Improvement of antioxidant status in vitamin E supplemented groups is in agreement with earlier findings $[1,16,31,33,34,41]$.

Increased TNF- $\alpha$ has been repeatedly shown to play a pivotal role in LPS-induced liver injury $[5,44]$. TNF- $\alpha$ is a multifunctional cytokine secreted by activated macrophages, monocytes, neutrophils and NK-cells. In addition to its direct cytotoxic effects, it is able to induce chemokines, (c) 2010 by NWPII. All rights reserved. 
macrophage chemotactic protein-1 and vascular cell adhesion molecule-1, which are the key to hyper inflammation and consequent liver damage [45-48]. Cellular sensitivity or resistance to TNF- $\alpha$ is correlated with decreased or increased levels of SOD respectively [49-51]. In the present study also, increased levels of TNF- $\alpha$ after LPS injection correlated with the increased level of peroxidation and decreased activities of SOD and catalase. Tocopherol significantly decreased the levels of TNF- $\alpha$ in LPS challenged groups. Corroborating with the present data, Bellezzo and colleagues [52] have shown that tocopherol suppresses LPSmediated activation of TNF- $\alpha$ production by Kupffer cells, suggesting thereby that vitamin E, in addition to inhibiting oxidative stress within hepatocytes, may also act to suppress Kupffer cell activation during liver injury.

In conclusion, the potential of vitamin $\mathrm{E}$ to maintain hepatic architechture along with significant decreases in biochemical parameters indicative of oxidative stress suggest the usage of vitamin $\mathrm{E}$ as an efficient strategy for the prophylactic management of LPS-induced liver tissue injury.

\section{Acknowledgement}

The authors are grateful to the Indian Council of Medical Research (ICMR), New Delhi, India, for providing financial assistance to carry out this research work. The authors also express their gratitude to Dr. B. N Datta, Ex-Professor of Pathology, Post Graduate Institute of Medical Education and Research, Chandigarh for providing help in the histological analysis of the samples.

\section{References}

1. Kheir-Eldin, A.A.; Motawi, T.K.; Gad, M.Z.; Abd-ElGawad, H.M. Protective effect of vitamin E, $\beta$-carotene and $N$-acetylcysteine from the brain oxidative stress induced in rats by lipopolysaccharide, Int J Biochem Cell B, 2001, 33, 475-482.

2. Berg, B.M.; Godbout, J.P.; Kelley, K.W.; Johnson, R.W. Alpha-tocopherol attenuates lipopolysaccharide-induced sickness behavior in mice, Brain Behav Immun, 2004, 18, 149157.

3. Kanter, M.; Coskun, O.; Armutcu, F.; Uz, Y.H.; Kizilay, G. Protective effects of vitamin $\mathrm{C}$, alone or in combination with vitamin $\mathrm{A}$, on endotoxin-induced oxidative renal tissue damage in rats, Tohoku J Exp Med, 2005, 206, 155-162.

4. Barreiros, A.P.; Schirmacher, P.; LaufenbergFeldmann, R.; Meyer Zum Buschenfelde, K.H.; Schlaak, J.F. The early immune response in the liver of BALB/c infected with S. typhimurium, Scand J Immunol, 2000, 51, 472-478.

5. $\mathrm{Su}, \mathrm{G} . \mathrm{L}$. Lipopolysaccharides in liver injury: molecular mechanisms of Kupffer cell activation, Am J Physiol Gastrointest Liver Physiol, 2002, 283, G256-265.

6. Victor, V.M.; Minano, M.; Guayerbas, N.; Del Rio, M.; Medina, S.; Fuente, M.D.L. Effects of endotoxic shock in several functions of murine peritoneal macrophages, Mol Cell Biochem, 1998, 189, 25-31.

7. Victor, V.M.; Guayerbas, N.; Garrote, D.; Del Rio, M.; Fuente, M.D.L. Modulation of murine macrophage function by $\mathrm{N}$-acetylcysteine in a model of endotoxic shock, Biofactors, 1999, 10, 347-357.

8. Victor. V.M.; Guayerbas, N.; Puerto, M.; Medino, S.; Fuente, M.D.L. Ascorbic acid modulates in vitro the function of macrophages from mice with different models of endotoxic shock, Immunopharmacol, 2000, 46, 89-101.

9. Victor, V.M.; Fuente, M.D.L. Changes in the superoxide production and other macrophage functions could be related to the mortality of mice with endotoxin- induced oxidative stress, Physiol Res, 2003, 52, 101-110.

10. Levy, E.; Ruebner, B.H. Hepatic changes produced by a single dose of endotoxin in the mouse. Light-microscopy and histochemistry, Am J Pathol, 1967, 51, 269-285.

11. Richard,C.; Lemonnier, F.; Thibault, M.; Couturier, M.; Auzepy, P. Vitamin E deficiency and lipoperoxidation during adult respiratory distress syndrome, Crit Care Med, 1990,18, 4-9. 
12. Thomas, J.A. Oxidative stress, oxidant defense and dietary constituents. In: Maurice, E., Shils, M.E., Olson, J.A., Shike, M., Eds. Modern Nutrition in Health and Disease, Awaverly, Philadelphia; 1994; pp 501-512.

13. Gupta, A.; Vij, G.; Sharma, S.; Tirkey, N.; Rishi, P.; Chopra, K. Curcumin, a polyphenolic antioxidant, attenuates chronic fatigue syndrome in murine water immersion stress model, Immunobiol, 2009, 214, 33-39.

14. Cadenas, S.; Cadenas, A.M. Fighting the stranger-antioxidant protection against endotoxin toxicity, Toxicol, 2002, 180, 45-63.

15. Bulger, E.M.; Maier, R.V. An argument for vitamin $\mathrm{E}$ supplementation in the management of systemic inflammatory response syndrome, Shock, 2003, 19, 99-103.

16. Gulec, M.; Gurel, A.; Armutcu, F. Vitamin E protects against oxidative damage caused by formaldehyde in the liver and plasma of rats, Mol Cell Biochem, 2006, 290, 61-67.

17. Ognjanović, B.I.; Pavlović, S.Z.; Maletić, S.D.; Zikić, R.V.; Stajn, A.S.; Radojicić, R.M.; Saicić, Z.S.; Petrović, V.M. Protective influence of vitamin $\mathrm{E}$ on antioxidant defense system in the blood of rats treated with cadmium, Physiol Res, 2003, 52, 563-570.

18. Soylu, A.R.; Aydogdu, N.; Basaran, U.N.; Altaner, S.; Tarcin, O.; Gedik, N.; Umit, H.; Tezel, A.; Dokmeci, G.; Baloglu, H.; Ture, M.; Kutlu, K.; Kaymak, K. Antioxidants vitamin E and $\mathrm{C}$ attenuate hepatic fibrosis in biliaryobstructed rats, World J Gastroenterol, 2006,12, 6835-6841.

19. Gurel, A.; Coskun, O.; Armutcu, F.; Kanter, M.; Ozen, O.A. Vitamin E against oxidative damage caused by formaldehyde in frontal cortex and hippocampus: biochemical and histological studies, J Chem Neuroanat, 2005, 29, 173-178.

20. Aldana, L.; Tsutsumi, V.; Craigmill, A.; Silveria, M.I.; Mejia, E.G. Alpha-tocopherol modulates liver toxicity of pyrethroid cypermethrin, Toxicol Lett, 2001, 125, 107116.

21. Atessahin, A.; Yilmaz, S.; Karahan, I.; Pirincci, I.; Tasdemir, B. The effects of vitamin $\mathrm{E}$ and selenium on cypermethrin- induced oxidative stress in rats, Türk $J$ Vet Anim Sci, 2005, 29, 385-391.

22. Avanzo, J.L.; Jr De Mendonca, C.X.; Pugine, S.M.; De Cerqueira Cesar, M. Effect of vitamin $\mathrm{E}$ and selenium on resistance to oxidative stress in chicken superficial pectoralis muscle, Comp Biochem Physiol C Toxicol Pharmacol, 2001, 129, 163-173.

23. Giray, B.; Gurbay, A.; Hincal, F. Cypermethrin-induced oxidative stress in rat brain and liver is prevented by vitamin $\mathrm{E}$ or allopurinol, Toxicol Lett, 2001, 118, 139-146.

24. Kale, M.; Rathore, N.; John, S.; Bhatnagar, D. Lipid peroxidative damage on pyrethroid exposure and alterations in antioxidant status in rat erythrocytes: a possible involvement of reactive oxygen species, Toxicol Lett, 1999, $105,197-205$.

25. Rocksén, D.; Ekstrand-Hammarström, B.; Johansson, L.; Bucht, A. Vitamin E reduces transendothelial migration of neutrophils and prevents lung injury in endotoxin-induced airway inflammation, Am J Respir Cell Mol Biol, 2003, 28, 199-207.

26. Wills, E.D. Mechanisms of lipid peroxide formation in animal tissues, Biochem J, 1966, 99, 667-676.

27. Lowry, O.H.; Rosenbrough, N.J.; Farr, A.L.; Randell, R.J. Protein measurement with Folin's phenol reagent, J Biol Chem, 1951, 193, 265-275.

28. Jollow, D.; Mitchell, L.; Zampaglione, N.; Gillete, J. Bromobenzene induced liver necrosis: protective role of glutathione and evidence for 3, 4-bromobenzenoxide as the hepatotoxic intermediate, Pharmacol, 1974, 11, 151-169.

29. Kono, Y. Generation of superoxide radical during autooxidation of hydroxylamine and an assay for superoxide dismutase, Arch Biochem Biophys, 1978, 186, 189-195.

30. Luck, H. Catalase. In: Bergmeyer, H.U. ed. Methods of Enzymatic Analysis, New York, Academic Press, 1971, pp 885-894.

31. Bansal, A.K.; Bansal, M.; Soni, G.; Bhatnagar, D. Protective role of vitamin E pre-treatment on $N$-nitrosodiethylamine induced oxidative stress in rat liver, Chem-Biol Interact, 2005, 156, 101-111. 
32. Montilla, P.; Cruz, A.; Padillo, F.J.; Túnez, I.; Gascon, F.; Muñoz, M.C.; Gómez, M.; Pera, C. Melatonin versus vitamin $\mathrm{E}$ as protective treatment against oxidative stress after extrahepatic bile duct ligation in rats, J Pineal Res, 2001, 31, 138-144.

33. Onyema, O.O.; Farombi, E.O.; Emerole, G.O.; Ukoha, A.I.; Onyeze, G.O. Effect of vitamin E on monosodium glutamate induced hepatotoxicity and oxidative stress in rats, Indian J Biochem Biophys, 2006, 43, 20-24.

34. Rao, M.V.; Parekh, S.S.; Chawla, S.L. Vitamin E supplementation ameliorates chromium and/or nickel-induced oxidative stress in vivo, J Health Sci, 2006, 52,142-147.

35. Coşkun, O.; Yakan, B.; Öztaş, E.; Sezen, S.; Günaydin, A.A. Antioxidant and hepatoprotective activity of vitamin $\mathrm{E}$ and $\mathrm{EGb} 761$ in experimental endotoxemic rats, Turk J Med Sci, 2000, 30, 427-432.

36. Singh, U.; Devaraj, S.; Jialal, I. Vitamin E, oxidative stress, and inflammation, Annu Rev Nutr, 2005, 25, 151-174.

37. Di Mascio, P.; Devasagayam, T.P.; Kaiser, S.; Sies, H. Carotenoids, tocopherols and thiols as biological singlet molecular oxygen quenchers, Biochem Soc Trans, 1990, 18, 1054-1056.

38. Packer, L.; Landvik, S. Vitamin E in biological systems, Adv Exp Med Biol, 1990, 264, 93-103.

39. Sakamoto, W.; Fujie, K.; Handa, H.; Ogihara, T.; Mino, M. In vivo inhibition of superoxide production and protein kinase $\mathrm{C}$ activity in macrophages from vitamin E-treated rats, Int $J$ Vitam Nutr Res, 1990, 60, 338-342.

40. Fantone, J.C.; Ward, P.A. Role of oxygenderived free radicals and metabolites in leukocyte-dependent inflammatory reactions, Am J Pathol, 1982, 107, 397-418.

41. Zaidi, S.M.K.R.; Banu, N. Antioxidant potential of vitamins $\mathrm{A}, \mathrm{E}$ and $\mathrm{C}$ in modulating oxidative stress in rat brain, Clin Chim Acta, 2004, 340, 229-233.

42. Lunec, J. Free radicals: Their involvement in disease processes, Ann Clin Biochem, 1990, 27,173-182.

43. Nistico, G.; Ciriolo, M.R.; Fiskin, K.; Iannone, M.; De Martino, A.; Rotilio, G. NGF restores decrease in catalase activity and increases superoxide dismutase and glutathione peroxidase activity in the brain of aged rats, Free Radic Biol Med, 1992, 12, 177-181.

44. Eastin, C.E.; McClain, C.J.; Lee, E.Y.; Bagby, G.J.; Chawla, R.K. Choline deficiency augments and antibody to tumor necrosis factor-alpha attenuates endotoxin-induced hepatic injury, Alcohol Clin Exp Res, 1997, 21, 1037-1041.

45. Arthur, M.J.; Bentley, I.S.; Tanner, A.R.; Saunders, P.K.; Millward-Sadler, G.H.; Wright, R. Oxygen-derived free radicals promote hepatic injury in the rat, Gastroenterology, 1985, 89, 1114-1122.

46. Muto, Y.; Nouri-Aria, K.T.; Meager, A.; Alexander, G.J.; Eddleston, A.L. Williams R. Enhanced tumour necrosis factor and interleukin-1 in fulminant hepatic failure, Lancet, 1988, 2, 72-74.

47. Nagakawa, J.; Hishinuma, I.; Hirota, K.; Miyamoto, K.; Yamanaka, T.; Tsukidate, K.; Katayama, K.; Yamatsu I. Involvement of tumor necrosis factor- $\alpha$ in the pathogenesis of activated macrophage- mediated hepatitis in mice, Gastroenterology, 1990, 99, 758-765.

48. Wang, H.; Wei, W.; Shen, Y.X.; Dong, C.; Zhang, L.L.; Wang, N.P.; Yue, L.; Xu, S.Y. Protective effect of melatonin against liver injury in mice induced by Bacillus CalmetteGuerin plus lipopolysaccharide, World J Gastroenterol, 2004, 10, 2690-2696.

49. Rishi, P.; Kaur, H.; Tirkey, N.; Chopra, K.; Bharrhan, S.; Chanana, V.; Koul, A. Are the increases in local tumour necrosis factor and lipid peroxidation observed in pre-starved mice infected with Salmonella typhimurium markers of increased liver damage? Microbes Infect, 2006, 8(7), 1695-1701.

50. Chanana, V.; Majumdar, S.; Rishi, P. Involvement of caspase-3, lipid peroxidation and TNF-alpha in causing apoptosis of macrophages by coordinately expressed Salmonella phenotype under stress conditions, Mol Immunol, 2007, 44, 1551-1558.

51. Hirose, K.; Longo, D.L.; Oppenheim, J.J.; Matsushima, K. Over expression of mitochondrial manganese superoxide dismutase promotes the survival of tumor cells 
exposed to interleukin-1, tumor necrosis factor, selected anti cancer drugs, and ionizing radiation, FASEB J, 1993, 7, 361-368.

52. Bellezzo, J.M.; Leingang, K.A.; Bulla, G.A.; Britton, R.S.; Bacon, B.R.; Fox, E.S.
Modulation of lipopolysaccharide-mediated activation in rat Kupffer cells by antioxidants, J Lab Clin Med, 1998, 131, 36-44. 